\title{
Complete reuse of raw fishmeal wastewater: Evidence from a field cultivation study and economic analysis
}

\author{
Jang Ho Kang, Hyun Yi Jung, Joong Kyun Kim ${ }^{\dagger}$ \\ Department of Biotechnology and Bioengineering, Pukyong National University, Busan 485137, Republic of Korea
}

\begin{abstract}
To examine the feasibility of reuse of raw fishmeal wastewater, it was biodegraded by a microbial consortium in a $1-\mathrm{m}^{3}$ reactor, and the final culture broth including mixed microbes was applied as biofertilizer to field cultivation of lettuce and Chinese cabbage. Moreover, economic analysis of the entire process was performed. A stable metabolism of organic matter degradation for $80 \mathrm{~h}$ with sufficient dissolved oxygen produced an amino acid content of $14.66 \mathrm{~g}$ per $100 \mathrm{~g}$ sample, along with increased cation and anion concentrations. The concentrations of $\mathrm{N}, \mathrm{P}$ and $\mathrm{K}$ in the final culture broth were $2.26,0.87$ and $0.65 \%$, respectively, while those of heavy metals were very low. In field cultivation of the two leafy vegetables, the biodegraded fishmeal wastewater showed better fertilizing ability than commercial fertilizers because of its high amino acid content. In addition, no external damage to leaves by the fertilization was observed. In economic analysis, the expected profitability from the practical reuse of raw fishmeal wastewater was estimated to be $\$ 491.68$ per a single biodegradation, which corresponds to $\$ 25,567.36$ per year. As a result, the complete reuse of fishmeal wastewater could be feasible and provide essential benefits.
\end{abstract}

Keywords: Biofertilizer, Complete reuse, Economic analysis, Field cultivation, Fishmeal wastewater

\section{Introduction}

Global fish consumption has shown a steady increase because fish is considered a protein food. However, this causes some environmental problems, because only about $40 \%$ of the fish product is consumed by humans and the remainder is waste [1]. Another problem is the generation of a large quantity of wastewater during fish processing. For this reason, the efficient disposal of fish waste and/or wastewater attracts our attention to help avoid environmental impacts.

Until recent years, fish waste and wastewater have been either used as low market-value products, or customarily dumped into the sea, causing a serious environmental impact. Therefore, environmentally acceptable biodegradation of fish waste and wastewater using microbes has been diversely applied to enhance the reutilization value of these waste products [2]. As one of these applications, biodegraded fish-processing wastewater may be reused as liquid fertilizer [2,3], because it can provide nutrients, mostly associated with hormones, organics or amino acids, for plant growth, and can also improve soil health [4].
Similarly, natural organic fertilizer made from foliage has been reported to be effective for feeding plants in soil that is deficient in or contains unavailable forms of nutrients, because plants absorb nutrients through their roots and foliage [5]. Amino acids function as precursors for essential biomolecules such as vitamins, cofactors, antioxidants and many defense compounds. In addition, amino-acid biosynthesis in young plants is known to be regulated by the metabolite network that links nitrogen assimilation with carbon metabolism [6, 7]. As a result, biodegraded fish-processing wastewater can be used as a substitute fertilizer that overcomes the weaknesses of chemical fertilizers such as deterioration in soil quality and the environment [8].

Biofertilizers are composed of beneficial microbes that colonize the rhizosphere or the inside of the plant. They can convert insoluble forms of plant nutrients into soluble forms [9]. Microbes reasonably used as biofertilizers include nitrogen fixers, potassium solubilizers, and phosphorus solubilizers [10]. In recent years, there has been increased interest in the use of beneficial microbes to improve soil fertility. Plant-growth-promoting bacteria reduce susceptibility to diseases caused by plant pathogens, and improve tolerance of stress conditions such as drought,

Received November 22, 2017 Accepted February 24, 2018

${ }^{\dagger}$ Corresponding author

Email: junekim@pknu.ac.kr

Tel: +82-51-629-5866 Fax: +82-51-629-5863

ORCID: 0000-0001-7070-9507

Copyright (C) 2018 Korean Society of Environmental Engineers
Conted the original work is properly cited. 
salinity and nutrient deficiency [11-13]. Bacillus species can survive as spores, alter the microbial composition of soil, transform soil nutrients into useful forms, and function in the soil carbon, nitrogen and sulfur cycles $[14,15]$. They also act as biocontrol agents because they can produce diverse antiviral, antibacterial, and antifungal compounds, impacting on other soil microbes [16]. Biofertilizer produced from the degradation of mackerel wastewater by Bacillus species showed antioxidant, antibacterial, and antifungal activities, and was potentially useful when applied to lab-scale hydroponics [2].

Another attempt at the biodegradation of fishmeal wastewater using aerobic microbes to turn it into a useful biofertilizer has been reported and was successful at the lab-scale [17]. The complete reuse of fishmeal wastewater as biofertilizer following biodegradation may be economically worthwhile because no additional wastewater remains after the biodegradation process. A scaled-up biodegradation for commercialization of fishmeal wastewater was executed in a $1-\mathrm{m}^{3}$ reactor, based on the lab-scale results [18]. Such efforts toward resource recycling with zero-waste emission are important to follow governmental waste policies that urge ecologically acceptable waste management [19]. Nevertheless, there have not yet been field tests of the fertilizing ability of biodegraded fishmeal wastewater (BFW), although such tests are essential for practical use. Lab-scale results of biofertilizer tests have limited appeal to fertilizer consumers, while field experiments have several benefits [20]. Through field experiments, farmers can verify whether lab-scale research applies to field scales in their farm environment and management practices. They are also able to test the recommendations of agricultural extension services in most kinds of production conditions. Tests of equipment, systems or technology packages are other benefits. Moreover, the expense of field experiment trials is lower than that of experiments at research institutes. In this study, therefore, a field test of BFW was performed to assess its fertilizing ability. For practical use, the biodegradation of fishmeal wastewater using mixed microbes was carried out in a pilot-scale reactor. The experimental plants for the field test were Chinese cabbage and lettuce, which are consumed in Korea in large quantities. Furthermore, the commercial value of fishmeal wastewater as a biofertilizer was analyzed.

\section{Materials and Methods}

\subsection{Microbes}

The microbes used in this study were eleven organic-matter-degrading bacteria reported in previous studies [21, 22]. Without any antagonism among them, the eleven microbes comprised a microbial consortium containing: Bacillus subtilis (DQ219358), Bacillus coagulans (AF466695), Bacillus circulans (Y13064), Bacillus anthracis (AY138279), Brevibacillus agri (AY319301), Bacillus licheniformis (AY468373), Bacillus fusiformis (AY548950), Bacillus cereus (DQ923487), Brevibacillus agri (AJ586388), Bacillus licheniformis (EF113324) and Brevibacillus paravrevis (AB215101). Each pure strain was maintained on nutrient agar plates at $4^{\circ} \mathrm{C}$ and transferred to a fresh agar plate every 2 weeks for the maintenance of cell viability. The degradation ability of each strain was periodically checked on $1 \%(\mathrm{w} / \mathrm{v})$ skim milk agar (for proteolysis) and 3.215\% (w/v) spirit blue agar (for lipolysis), respectively. All agar plates used in the degradation ability tests were incubated at $45^{\circ} \mathrm{C}$. For the preparation of inoculum used for the biodegradation of fishmeal wastewater, each strain was separately cultivated until the late log-phase and then equal amounts of cells of each strain were combined to construct the microbial consortium.

\subsection{Biodegradation of Fishmeal Wastewater}

The fishmeal wastewater used in this study was obtained from a local fishmeal processing plant. Initial values of chemical oxygen demand $\left(\mathrm{COD}_{\mathrm{Cr}}\right)$, total nitrogen $(\mathrm{TN}), \mathrm{NH}_{4}{ }^{+}-\mathrm{N}$, and $\mathrm{NO}_{3}{ }^{-} \mathrm{N}$ of the fishmeal wastewater were $116,800,11,980,366.8$, and $107.5 \mathrm{mg} / \mathrm{L}$, respectively. For the biodegradation, a $1-\mathrm{m}^{3}$ reactor was washed with tap water containing $0.5 \%(\mathrm{w} / \mathrm{v})$ sodium hydroxide, and then sterilized by hot steam at $3 \mathrm{~kg} / \mathrm{cm}^{2}$ for $30 \mathrm{~min}$. After the reactor was prepared, $600 \mathrm{~L}$ of fishmeal wastewater, which was boiled at $80^{\circ} \mathrm{C}$ for $3 \mathrm{~h}$, was pumped into the reactor at $600 \mathrm{~L} / \mathrm{h}$. After the reactor temperature cooled to $45^{\circ} \mathrm{C}, 110$ $\mathrm{g}$ (wet weight) of the microbial consortium were inoculated into the reactor. The seeded cells were previously acclimated for $1 \mathrm{~d}$ in sterile fishmeal wastewater under an aerobic condition. During the biodegradation, the reactor temperature was maintained at $45 \pm 2^{\circ} \mathrm{C}$ and oxygen was continuously supplied using an oxygen generator $(25 \mathrm{~L} / \mathrm{min}$ and $90 \pm 3 \%$ purity) and booster (120 L/min). Ten-fold diluted antifoam agent (Antifoam 204; Sigma-Aldrich, USA) was used whenever severe foaming occurred. The discharge gas passed through two consecutive flasks (10 L each) containing $10 \mathrm{M}$ sodium hydroxide to prevent contamination from the outside. The two flasks were put in ice to collect evaporated water from the discharging air. The deficit water was replenished just after sampling. Samples were periodically taken from the reactor to measure major reaction parameters. All measurements were carried out in triplicate. After the absence of pathogenic bacteria was confirmed, the entire 80-h BFW including cells was used in later field experiments.

\subsection{Field Experiments on BFW}

The fertilizing ability of the $80-\mathrm{h}$ BFW was tested in fields. The field experiments were performed from March to May at a farm attached to the College of Nature Resource and Life Science, Pusan National University, Korea. Twenty-four lots $(20 \mathrm{~m} \times 12 \mathrm{~m})$ were provided for this field experiment, and a Chinese cabbage (Brassica rapa L. ssp. pekinensis) and a lettuce (Lactuca sativa L.) were used as the test plants. The lots, on sandy-loam soil (15 cm depth), were divided into four $\left(60 \mathrm{~m}^{2}\right.$ each): three zones for fertilization (by BFW and two organic fertilizers (OF) widely sold in Korea, respectively) and one zone as a control without fertilization. Each zone was further divided into three $\left(20 \mathrm{~m}^{2}\right.$ each $)$ to make three replication experiments possible for each treatment. Seeding was conducted in a hotbed, and transplanting to the field was carried out after $15 \mathrm{~d}$. Each young plant was planted with separation at a regular distance 
(15 $\mathrm{cm} \times 20 \mathrm{~cm}$ ), and thus 650 plants occupied each $20 \mathrm{~m}^{2}$ area. When roots were put down after $10 \mathrm{~d}$, fertilization by means of injection was practiced twice at an interval of $7 \mathrm{~d}$. All fertilizers used for field experiments were diluted 1,000-fold. When 2 weeks elapsed from the last fertilization, ten samples were taken individually from each of the four zones for the measurement of growth characteristics of each vegetable (number, length, area and width of leaves; fresh body weight; and yield of crop). The measurement was performed in triplicate. The external damage to leaves after fertilization was also examined six times in total, at intervals of $3 \mathrm{~d}$.

\subsection{Analytical Methods}

The concentrations of $\mathrm{Na}^{+}, \mathrm{NH}_{4}{ }^{+}, \mathrm{NO}_{3}{ }^{-}, \mathrm{PO}_{4}{ }^{3-}$ and $\mathrm{SO}_{4}{ }^{2-}$ during the biodegradation were examined by ion chromatography (Metrohm 792 Basic IC, Switzerland). For measurements of anion and cation concentrations, Metrosep C2-150 $(150 \times 4.0 \mathrm{~mm})$ and Metrosepsupp 5-150 $(150 \times 4.0 \mathrm{~mm})$ columns were used, respectively. The $\mathrm{COD}_{\mathrm{Cr}}$ and $\mathrm{TN}$ were determined using a water quality analyzer (Humas Co., Ltd., Korea). For the determination of dry-sludge weight (DSW), a 5-mL sample in an aluminum dish was weighed after being dried in an oven at $105^{\circ} \mathrm{C}$ for $12 \mathrm{~h}$. Change in cell density during the biodegradation was examined by counting colonies formed on agar plates, and are expressed in terms of colony forming unit (CFU) per $\mathrm{mL}$ of sample. To measure protease activity, $5 \mu \mathrm{L}$ of sample was periodically taken and dropped at the center of skim-milk agar plate. After incubation at $45^{\circ} \mathrm{C}$ for 1 day, the degree of protease activity was determined according to the size of a clear zone formed on the agar plate. Analyses of amino acid composition and the $\mathrm{N}, \mathrm{P}$ and K contents were performed by the Korea Basic Science Institute (Daejeon, Korea). Concentrations of heavy metals were determined by the Foundation of Agri. Tech. Commercialization and Transfer (Suwon, Korea). Absence or presence of any pathogenic bacteria in biofertilizer was analyzed by the Korea Testing and Research Institute (Gwacheon, Korea).

\subsection{Statistical Analysis}

Statistical analysis was performed on triplicate measurements obtained from field experiments. Sample observations were not arranged in a frequency distribution. Therefore, standard deviations were estimated according to the following procedures. Every deviation was squared, and the sum of the squares was divided by $(n-1)$, i.e. one less than the sample size (n). Then, the extraction of the square root recovered the original scale of measurement. The comparison of means was completed by the Tukey method [23] using the SAS program, with equal sample sizes. A difference was considered significant at $p<0.05$.

\subsection{Economic Analysis}

Economic analysis of the production and use of BFW as a biofertilizer was performed to assess the practicality of this process. The main process costs are capital investment and operation. The investment cost was calculated by multiplying the capital investment by an annuity factor, $k$, that is composed of interest rate and depreciation rate factors [24]:

$$
k=\frac{i}{1-(1+i)^{-t}}
$$

where $i$ is the interest rate factor and $t$ is the economic life time.

According to the evaluation used for typical types of bioprocess and equipment studied here, the interest rate and economic lifetime were set to $7 \%$ and $10 \mathrm{y}$, respectively [24]. The operation cost was estimated from cost parameters for: raw materials, chemicals, and utilities, and others including labor, maintenance and insurance [25]. The amounts of raw fishmeal wastewater and chemicals used in this study were derived from the process mass balances. It was assumed that the fishmeal manufacture was accompanied by biofertilizer production by efficient treatment of fishmeal wastewater. Therefore, only the cost of transportation from the fishmeal manufacturing plant to the biofertilizer production plant through pipes was considered for raw fishmeal wastewater. The cost of chemicals was obtained from laboratory chemical suppliers. Utility requirements included the cost of heating and pumping for sterilization, input and output of wastewater, and agitation, which were based on rule-of-thumb values [26]. The costs of maintenance and insurance were calculated as 10 and $15 \%$ of the annual capital investment cost, respectively [27].

\section{Results and Discussion}

\subsection{Biodegradation of Fishmeal Wastewater}

Prior to field experiments on biofertilizer which contained the final culture broth including mixed microbes, the fertilizer was first produced from fishmeal wastewater. The fishmeal wastewater was biodegraded in a pilot-scale reactor. Changes in major reaction parameters were examined during the biodegradation to be able to reproduce high-quality biofertilizer, and the results are shown in Fig. 1 and Fig. 2. The $\mathrm{COD}_{\mathrm{Cr}}$ and TN concentration in fishmeal wastewater decreased as the biodegradation proceeded (Fig. 1(a)). After $80 \mathrm{~h}$ of biodegradation, the $\mathrm{COD}_{\mathrm{Cr}}$ and TN were 30,000 and $3,820 \mathrm{mg} / \mathrm{L}$, respectively. The decreases of $\mathrm{COD}_{\mathrm{Cr}}$ and $\mathrm{TN}$ during biodegradation were 74.3 and $68.1 \%$, respectively. The lost $\mathrm{COD}_{\mathrm{Cr}}$ and $\mathrm{TN}$ were used mainly for cellular proliferation and production of metabolites including $\mathrm{CO}_{2}$ and $\mathrm{N}_{2}$. The results obtained from this study showed more biodegradation compared with the lab-scale [21]. This indicates that the biodegradation was significantly dependent upon available DO ( $>1 \mathrm{mg} / \mathrm{L})$. In the biodegradation of organic matter, metabolism may be dependent upon the COD/TN ratio [28]. The ratio of $\mathrm{COD}_{\mathrm{Cr}} / \mathrm{TN}$ in this study decreased a little, from 9.7 to 7.9 , implying a stable metabolism of organic matter degradation [18].

Under continuous supply of pure oxygen into the reactor, the initial $\mathrm{pH}$ was 6.86; it increased to 6.99 after the first 6 $\mathrm{h}$, decreased to 5.80 after the next $24 \mathrm{~h}$, and then decreased slowly to 5.69 after $80 \mathrm{~h}$ of biodegradation (Fig. 1(b)). This result implies that the microbial consortium used in this study adapted for $6 \mathrm{~h}$ and then started to degrade the fishmeal wastewater 


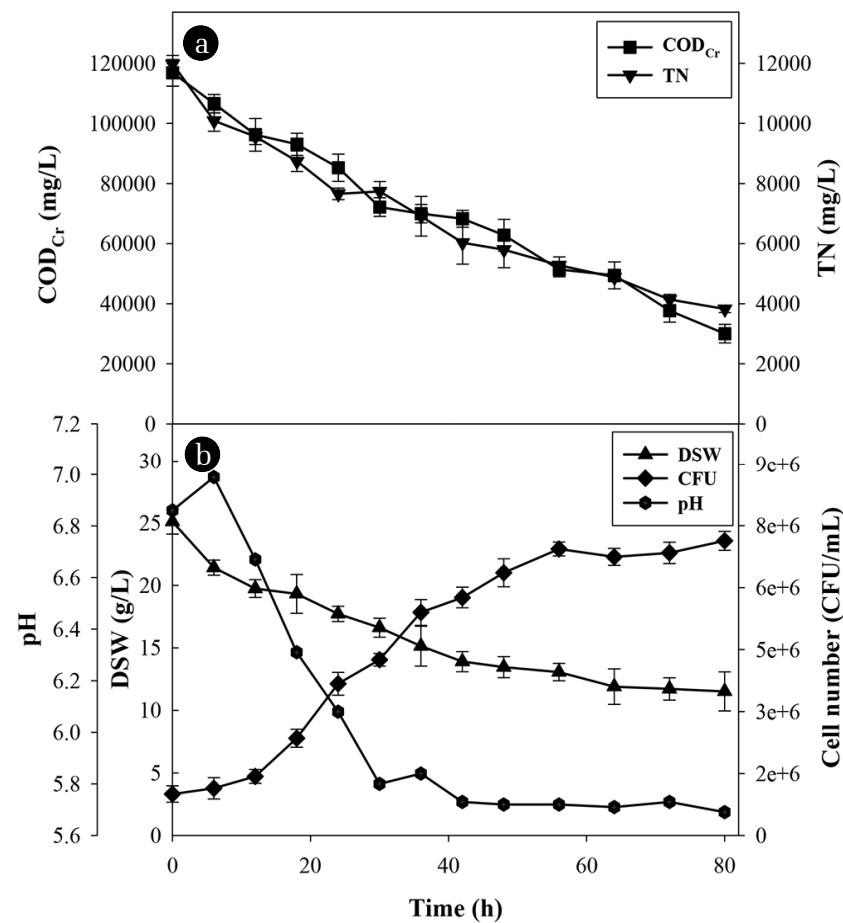

Fig. 1. Changes in the reaction parameters during the biodegradation of fishmeal wastewater in a $1-\mathrm{m}^{3}$ reactor. (a) $\mathrm{COD}_{\text {cr }}$ and $\mathrm{TN}$; and (b) DSW, cell number and $\mathrm{pH}$. Error bars represent the standard deviations of the mean values of three replicates.

components. The main component, protein, was depolymerized primarily by extracellular proteinases and yielded small peptides and amino acids, causing a pH drop [29]. After $30 \mathrm{~h}$, the unpleasant fishy smell disappeared. This result indicates that sufficient DO was used in this biodegradation, since the objectionable smell is easily produced in insufficiently aerobic conditions [30]. The fast disappearance of odors is an important criterion by which to judge an appropriate treatment process, since civil petitions often object to odor emission. As the microbial consortium degraded fishmeal wastewater components actively, the DSW changed from 25.10 to $11.52 \mathrm{~g} / \mathrm{L}$, representing a $54.1 \%$ reduction, and the cell number increased from $1.00 \times 10^{6}$ to $7.13 \times 10^{6} \mathrm{CFU} / \mathrm{mL}$. Therefore, fishmeal wastewater components, as both substrate and energy sources, contributed to the growth of the microbial consortium. As the biomass increased, the total amounts of proteases for the degradation of the available substrates increased by secretion from the microbes, stimulating biodegradation. In the analysis of mixed microbes in final culture broth, no pathogenic bacteria was detected.

Fig. 2 shows changes in the concentrations of cations and anions during the biodegradation. The concentration of $\mathrm{Na}^{+}$ did not show any significant change, while that of $\mathrm{NH}_{4}{ }^{+}$steadily increased, from 366.8 to $770.7 \mathrm{mg} / \mathrm{L}$ after $80 \mathrm{~h}$ (Fig. 2(a)). $\mathrm{NH}_{4}{ }^{+}$ may be produced through the biodegradation of protein-rich materials [31]. Increase in $\mathrm{NH}_{4}{ }^{+}$also resulted from cell autolysis. After $60 \mathrm{~h}$, this phenomenon revealed prominently when cells reached a stationary phase. These results agreed with those

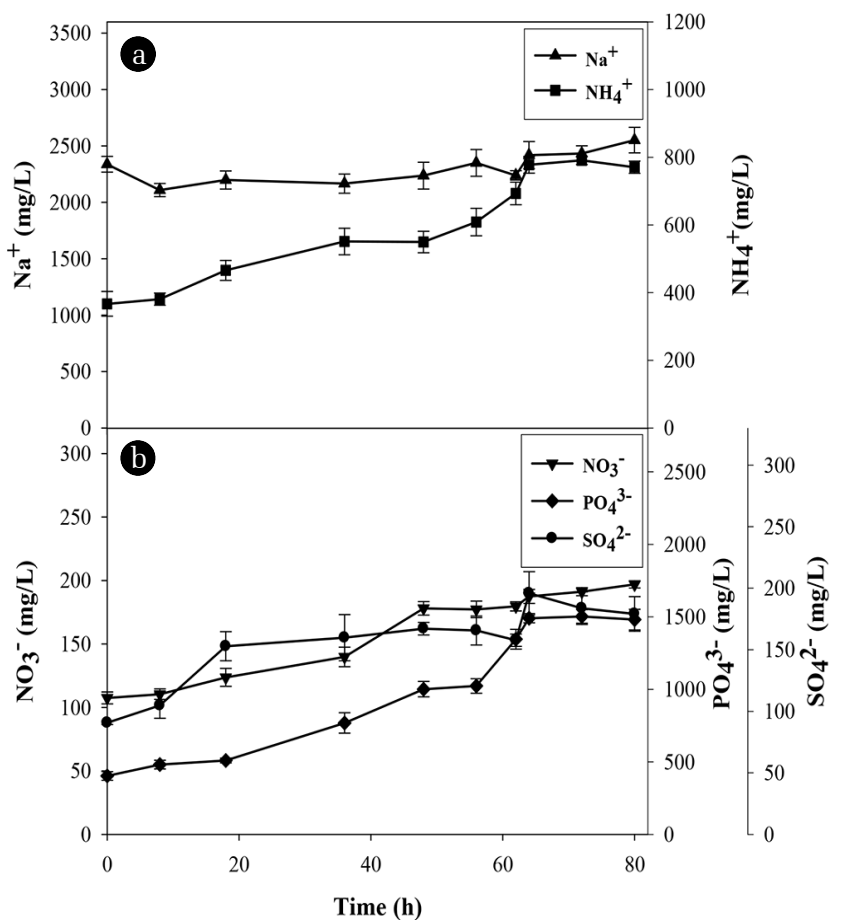

Fig. 2. Changes in the concentrations of cations (a) and anions (b) during the biodegradation of fishmeal wastewater in a $1-\mathrm{m}^{3}$ reactor. Error bars represent the standard deviations of the mean values of three replicates.

reported in a previous study [22]. The concentrations of all tested anions steadily increased during the biodegradation (Fig. 2(b)). After $80 \mathrm{~h}$, the final concentrations of $\mathrm{NO}_{3}{ }^{-}, \mathrm{PO}_{4}{ }^{3-}$ and $\mathrm{SO}_{4}{ }^{2-}$ were $196.9,1,480.4$ and $179.1 \mathrm{mg} / \mathrm{L}$, respectively. Some of the produced amino acids were utilized by the microbes and converted to $\mathrm{CO}_{2}$ and $\mathrm{NO}_{3}{ }^{-}$. Therefore, the concentration of $\mathrm{NO}_{3}{ }^{-}$ was steadily increased as the biodegradation proceeded. When oxygen availability was sufficient during the biodegradation, aerobic decomposition of the organics present in the fishmeal wastewater could produce harmless, stable products, such as carbon dioxide, sulfate, orthophosphate, and nitrate. Therefore, the increases in anion concentrations imply that the biodegradation was executed in aerobic conditions. Ultimately, the increases in cation and anion concentrations during the biodegradation could help enhance the quality of the resulting product biofertilizer. The combined use of organics and inorganics can promote nutrient use efficiency, and is essential for planting [32].

\subsection{Fertilizing Ability of BFW}

Fishmeal wastewater is known to contain valuable resources including carbohydrates, proteins, fats, and minerals, and relatively low concentrations of toxic substances including heavy metals [33]. Amino acids are an active portion of the organic matter in a fertilizer, because they are an important nitrogen source in natural ecosystems [34], and the availability of a suitable balance of amino acids is essential for the growth of plants. Considering the importance of essential amino acids, their com 
position in BFW was measured (Table 1). Through the 80-h biodegradation, the total content of amino acids increased from 4.16 to $14.66 \mathrm{~g}$ per $100 \mathrm{~g}$ sample. The final content of amino acids was higher than those in the two commercial fertilizers, indicating that the biodegraded fishmeal waste is a rich source of amino acids. The levels of each specific amino acid present in BFW were diverse. The contents of aspartic acid, glutamic acid, glycine, threonine, alanine, methionine, isoleucine, phenylalanine and tryptophan were significantly increased by the biodegradation. The contents of glutamic acid, threonine, alanine, valine, methionine, isoleucine, leucine, phenylalanine, tryptophan and lysine were high compared with those in the two commercial fertilizers. The content of the sulfur-containing amino acid methionine was relatively high, and this feature could enhance the fertilization ability of BFW, because methionine is both a nutritionally essential amino acid and the precursor of several metabolites that regulate plant growth [35]. However, the levels of aspartic acid and proline were lower those in the two commercial fertilizers. Fish waste is generated at a level of approximately $60 \%$ during fish processing, and the extent of waste generation depends on the level of processing and the type of fish. The amino acid content varies in diverse fish waste. Nevertheless, a high degree of biodegradation must be performed

Table 1. Comparison of Amino Acid Composition in the Biodegraded Wastewater with Commercial Fertilizers

\begin{tabular}{|c|c|c|c|c|}
\hline \multirow{2}{*}{ Amino acids } & \multicolumn{4}{|c|}{ Source (g/100 g sample) } \\
\hline & Initial FW $^{*}$ & Final BFW ${ }^{\dagger}$ & $\mathrm{OF}^{*} \mathbf{1}$ & OF 2 \\
\hline Cysteine & 0.02 & 0.04 & n.d. ${ }^{\S}$ & 0.02 \\
\hline Aspartic acid & 0.02 & 0.34 & 0.72 & 0.59 \\
\hline Glutamic acid & 0.09 & 1.11 & 0.49 & 0.89 \\
\hline Glutamine & 0.08 & 0.21 & 1.08 & n.d. \\
\hline Glycine & 0.06 & 1.68 & 2.36 & 1.25 \\
\hline Threonine & 0.18 & 0.69 & 0.18 & 0.22 \\
\hline Alanine & 0.27 & 1.03 & 0.27 & 0.99 \\
\hline Serine & 0.06 & 0.21 & n.d. & 0.3 \\
\hline Proline & 0.33 & 0.40 & 0.96 & 0.61 \\
\hline Tyrosine & 0.11 & 0.14 & 0.33 & 0.05 \\
\hline Valine & 0.86 & 1.12 & 0.51 & 0.24 \\
\hline Methionine & 0.08 & 1.55 & 1.26 & n.d. \\
\hline Isoleucine & 0.22 & 1.02 & 0.38 & 0.14 \\
\hline Leucine & 0.68 & 1.08 & 0.22 & 0.26 \\
\hline Phenylalanine & 0.31 & 1.46 & 0.68 & 0.18 \\
\hline Tryptophan & n.d. & 0.97 & 0.31 & n.d. \\
\hline Lysine & 0.79 & 1.43 & 0.82 & 0.53 \\
\hline Arginine & n.d. & 0.18 & n.d. & 0.15 \\
\hline Total & 4.16 & 14.66 & 10.57 & 6.42 \\
\hline
\end{tabular}

* Fishmeal wastewater just before the biodegradation.

${ }^{\dagger}$ Biodegraded fishmeal wastewater just after the 80-h biodegradation.

\#rganic fertilizer widely sold in Korea.

$\S$ Not detected. in optimal conditions to produce quality fertilizer, and, thus, the content of amino acids can be used as a means of assessing biodegradation. In this study, the total level of amino acids present in BFW was higher than those present in the two commercial fertilizers, implying successful biodegradation by the microbial consortium used in this study.

The content of nutrients in fertilizers is a criterion to assess their fertilizing ability. The growth of plants is dependent upon inorganic nutrients as well as organic nutrients. For this reason, the concentrations of the three primary nutrients $(\mathrm{N}, \mathrm{P}$ and $\mathrm{K}$ ) and heavy metals present in BFW were analyzed and compared with those of the two commercial fertilizers (Table 2). The concentrations of $\mathrm{N}, \mathrm{P}$ and $\mathrm{K}$ were $2.26,0.87$ and $0.65 \%$, respectively, which were lower than those in the two commercial fertilizers. On the contrary, the concentrations of heavy metals were much lower than those in the commercial fertilizers. $\mathrm{Cd}, \mathrm{Ni}, \mathrm{Pb}$ and $\mathrm{Hg}$ were not detected in BFW, and the concentrations of other elements were below the standard concentration requirements of liquid fertilizers. The use of fertilizer is one source of heavy metal enrichment in soils. The contamination of agricultural soils by heavy metals can pose threats to human health and food safety because of heavy metal uptake by food crops [36]. In this respect, BFW was a good raw material for the production of a biofertilizer with low possibility of heavy metal contamination.

Table 2. Comparison of $\mathrm{N}, \mathrm{P}$ and $\mathrm{K}$ Contents and Heavy Metals in the Biodegraded Wastewater with Commercial Fertilizers

\begin{tabular}{lccc}
\hline \multicolumn{1}{c}{ Component } & BFW $^{*}$ & OF $^{\dagger} \mathbf{1}$ & OF 2 \\
$\mathrm{N}, \mathrm{P}, \mathrm{K}(\%)$ & & & \\
$\mathrm{N}$ & 2.26 & 3.67 & 1.57 \\
$\mathrm{P}_{2} \mathrm{O}_{5}$ & 0.87 & 2.89 & 1.95 \\
$\mathrm{~K}_{2} \mathrm{O}$ & 0.65 & 1.46 & 2.19 \\
$\mathrm{Heavy}$ metals (mg/kg) & & & \\
$\mathrm{Cd}$ & n.d. & n.d. & n.d. \\
$\mathrm{Cu}$ & 1.06 & 14.62 & 2.72 \\
$\mathrm{Ni}$ & n.d. & 0.37 & 2.16 \\
$\mathrm{~Pb}$ & n.d. & n.d. & 0.33 \\
$\mathrm{Zn}$ & 2.89 & 71.30 & 6.97 \\
$\mathrm{Hg}$ & n.d. & n.d. & n.d. \\
$\mathrm{Cr}$ & 0.79 & 17.57 & 3.30 \\
$\mathrm{As}$ & 0.22 & 4.71 & 2.94 \\
\hline
\end{tabular}

* Biodegraded fishmeal wastewater just after the 80-h biodegradation.

${ }^{\dagger}$ Organic fertilizer widely sold in Korea.

${ }^{\ddagger}$ Not detected.

\subsection{Field Experiments Using BFW}

Compared with lab-scale results, field experiments are much more interesting to fertilizer consumers [20]. For practical use, the 80-h BFW including mixed microbes was applied to field cultivation to test its fertilization ability, and compared with two commercial OFs. The effects of the three fertilizers on the growth of two vegetable crops (lettuce and Chines cabbage) are 
Table 3. The Effects of the Three Fertilizers on the Growth of Two Vegetable Crops, Lettuce and Chines Cabbage, Compared with the Unfertilized Control $^{*}$

\begin{tabular}{|c|c|c|c|c|c|}
\hline \multirow{2}{*}{ Vegetables } & \multirow{2}{*}{ Characteristics } & \multicolumn{3}{|c|}{ Fertilizers } & \multirow{2}{*}{ Control } \\
\hline & & BFW $^{\dagger}$ & $\mathrm{OF}^{*} 1$ & OF 2 & \\
\hline \multirow{9}{*}{ Lettuce } & Growth of leaf & & & & \\
\hline & Number (-) & $5.12 \pm 0.10^{\mathrm{w}}$ & $5.04 \pm 0.08^{\mathrm{w}}$ & $4.86 \pm 0.08^{\mathrm{x}}$ & $4.67 \pm 0.06^{\mathrm{y}}$ \\
\hline & Length (cm) & $15.6 \pm 0.3^{\mathrm{w}}$ & $15.2 \pm 0.3^{\mathrm{w}}$ & $14.4 \pm 0.3^{\mathrm{x}}$ & $13.7 \pm 0.2^{y}$ \\
\hline & Area $\left(\mathrm{cm}^{2}\right)$ & $37.2 \pm 0.3^{\mathrm{w}}$ & $36.4 \pm 0.2^{\mathrm{x}}$ & $32.4 \pm 0.4^{y}$ & $31.1 \pm 0.2^{z}$ \\
\hline & Width (cm) & $6.38 \pm 0.08^{\mathrm{w}}$ & $6.19 \pm 0.08^{\mathrm{x}}$ & $5.92 \pm 0.08^{y}$ & $5.89 \pm 0.06^{y}$ \\
\hline & Body weight (g) & $1.10 \pm 0.04^{w}$ & $1.07 \pm 0.03^{\mathrm{w}}$ & $0.98 \pm 0.03^{x}$ & $0.94 \pm 0.03^{x}$ \\
\hline & Yield of crop & & & & \\
\hline & per $20 \mathrm{~m}^{2}(\mathrm{~g})$ & $715.0 \pm 13.0^{\mathrm{w}}$ & $702.7 \pm 11.8^{\mathrm{w}}$ & $641.6 \pm 11.2^{\mathrm{x}}$ & $611.0 \pm 10.8^{y}$ \\
\hline & per $1,000 \mathrm{~m}^{2}(\mathrm{~kg})$ & $11.8 \pm 0.4^{\mathrm{w}}$ & $11.6 \pm 0.3^{\mathrm{w}}$ & $10.7 \pm 0.2^{\mathrm{x}}$ & $10.1 \pm 0.2^{\mathrm{y}}$ \\
\hline \multirow{9}{*}{$\begin{array}{l}\text { Chinese } \\
\text { cabbage }\end{array}$} & Growth of leaf & & & & \\
\hline & Number (-) & $12.2 \pm 0.2^{\mathrm{w}}$ & $11.4 \pm 0.2^{\mathrm{x}}$ & $10.8 \pm 0.2^{\mathrm{y}}$ & $10.2 \pm 0.2^{\mathrm{z}}$ \\
\hline & Length (cm) & $21.1 \pm 0.3^{w}$ & $19.8 \pm 0.4^{\mathrm{x}}$ & $19.1 \pm 0.4^{\mathrm{xy}}$ & $18.5 \pm 0.3^{y}$ \\
\hline & Area $\left(\mathrm{cm}^{2}\right)$ & $132.3 \pm 1.0^{\mathrm{w}}$ & $124.9 \pm 1.2^{\mathrm{x}}$ & $116.0 \pm 1.4^{y}$ & $111.5 \pm 1.2^{z}$ \\
\hline & Width (cm) & $12.9 \pm 0.2^{\mathrm{w}}$ & $12.0 \pm 0.3^{\mathrm{x}}$ & $11.6 \pm 0.2^{\mathrm{xy}}$ & $11.4 \pm 0.1^{\mathrm{y}}$ \\
\hline & Body weight (g) & $4.72 \pm 0.08^{w}$ & $4.52 \pm 0.10^{\mathrm{x}}$ & $4.20 \pm 0.12^{y}$ & $4.04 \pm 0.08^{y}$ \\
\hline & Yield of crop & & & & \\
\hline & per $20 \mathrm{~m}^{2}(\mathrm{~g})$ & $3,068.0 \pm 32.5^{\mathrm{w}}$ & $2,967.4 \pm 40.4^{\mathrm{x}}$ & $2,731.1 \pm 39.0^{\mathrm{y}}$ & $2,626.0 \pm 26.3^{z}$ \\
\hline & per $1,000 \mathrm{~m}^{2}(\mathrm{~kg})$ & $50.6 \pm 0.6^{\mathrm{w}}$ & $48.9 \pm 0.7^{\mathrm{x}}$ & $45.0 \pm 0.8^{y}$ & $43.3 \pm 0.6^{\mathrm{z}}$ \\
\hline
\end{tabular}

${ }^{*}$ Values (mean \pm SD of three replicates) in the same row not sharing a common superscript are significantly different $(p<0.05)$.

'Biodegraded fishmeal wastewater just after the 80-h biodegradation.

Organic fertilizer widely sold in Korea.

shown in Table 3 compared with the unfertilized control. The fertilizing effects on the leaf growth and crop yield were BFW $>$ OF $1>$ OF 2 for each vegetable, and this order was in accord with the amino acid-content in the fertilizers. This implies that the two vegetables used in this study are somewhat reliant on added amino acids for their growth. Similar results can be found in previous studies; it has been reported that practical use of sixteen essential amino acids improved lettuce crop uniformity [37], and that of four amino acids (glycine, alanine, lysine and glutamic acid) improved the quality of Chinese cabbage with increases in the sugar and protein content [38]. The enhancements in the number, length, area, width and fresh body weight of lettuce leaves by BFW were 10,14, 20, 10 and 17\% compared with the control, respectively. Those of Chinese cabbage by BFW were 20,14, 19, 13 and 17\% compared with the control, respectively. In addition, the ratios of the crop yields of lettuce and Chinese cabbage per $1,000 \mathrm{~m}^{2}$ on fertilization with the three fertilizers were calculated, since the total fresh weight of the vegetables is often used as an indicator of the vegetable yields [39]. The relative crop yields compared with the control after fertilizing with BFW, OF 1 and OF 2 were approximately 1.17, 1.15 and 1.05 for lettuce and 1.17, 1.13 and 1.04 for Chinese cabbage, respectively. The ratio of lettuce yield on fertilization with BFW was significantly different from that for OF 2 ( $p<$
0.05), while the ratio of Chinese cabbage yield on fertilization with BFW was significantly different from those for OF 1 or OF $2(p<0.05)$.

To observe the effects of the three fertilizers in terms of leaf growth, the growth ratios against the control were calculated (Fig. 3). Due to the differences in the content of amino acids, the fertilizing effects of BFW and OF 1 were significantly different from that of OF 2 in all cases $(p<0.05)$. The significant difference in fertilizing effect compared with the control was somewhat greater in Chinese cabbage than lettuce. This may result from the high content of four amino acids (glycine, alanine, lysine and glutamic acid) present in BFW (Table 1). Lettuce and Chinese cabbage used in this study are favorite leafy vegetables. Their leaf traits are good indicators of growth [40], and improving their growth is the primary function of fertilizer. Considering this fact, the fertilizing effects of BFW on both lettuce and Chinese cabbage were obvious, as verified through the field experiments. Furthermore, no external damage to leaves as a result of BFW fertilization was observed for either vegetable at any time after fertilization.

The practical use of BFW as a biofertilizer provides another benefit in the reuse of fishmeal wastewater. Microbes are an organic mass, generally represented as $\mathrm{C}_{5} \mathrm{H}_{7} \mathrm{O}_{2} \mathrm{~N}$. This organic compound is oxidized by two reactions: 


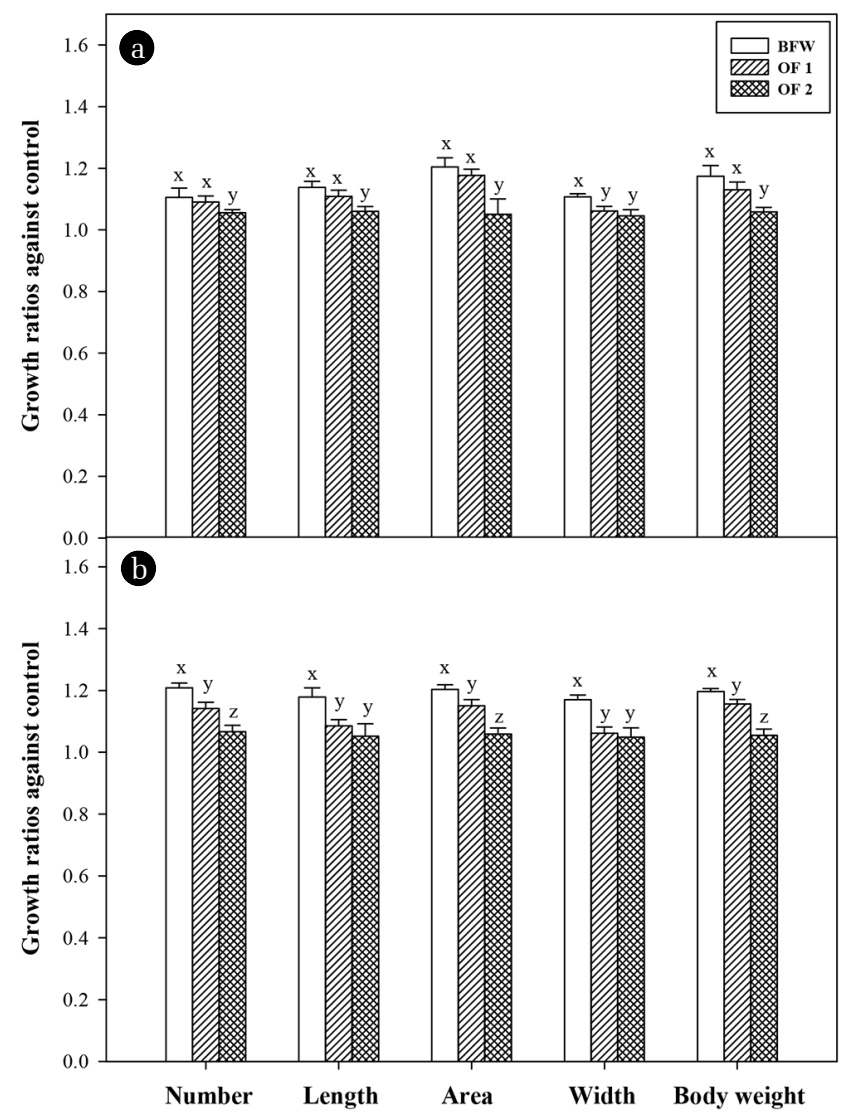

Fig. 3. The differences in the number, length, area, width and fresh body weight of lettuce (a) and Chinese cabbage (b) leaves by fertilization with three different fertilizers, compared with the control. The significances of differences between mean values are represented with letters $x, y$ and $z(p<0.05)$.

$$
\begin{gathered}
\mathrm{C}_{5} \mathrm{H}_{7} \mathrm{O}_{2} \mathrm{~N}+5 \mathrm{O}_{2} \rightarrow 5 \mathrm{CO}_{2}+2 \mathrm{H}_{2} \mathrm{O}+\mathrm{NH}_{3} \\
\mathrm{NH}_{3}+2 \mathrm{O}_{2} \rightarrow \mathrm{NO}_{3}^{-}+\mathrm{H}^{+}+\mathrm{H}_{2} \mathrm{O}
\end{gathered}
$$

Therefore, two "types" of oxygen are needed to oxidize this organic compound [41]: one to oxidize organic carbon to carbon dioxide, called the carbonaceous oxygen demand (CBOD), and the other to convert ammonia to nitrate, called the nitrogenous oxygen demand (NBOD). In this study, approximately $145 \mathrm{~g}$ of cells remained in each batch biodegradation in the $1-\mathrm{m}^{3}$ reactor (with $600 \mathrm{~L}$ working volume), which is equivalent to $342.2 \mathrm{mg} / \mathrm{L}$ of CBOD and $137.0 \mathrm{mg} / \mathrm{L}$ of NBOD based on the stoichiometry in Eq. (2) and (3). Thus, the theoretical total biological oxygen demand is $479.2 \mathrm{mg} / \mathrm{L}$, which is produced in every batch biodegradation. The microbes remaining after biodegradation must be disposed of unless they are used together with the culture broth supernatant in the liquid fertilizer. In general, the cells remaining after bioprocesses are treated by anaerobic digestion, which is a weakness of such bioprocesses. However, if the entire BFW is used as a biofertilizer, its value is enhanced by reduction of expenditure for treatment of the cells. Meanwhile, microbes in the biofertilizer have valuable functions, such as nitrogen fixation, potassium and phosphorus solubilization, and synthesis of growth-promoting substances, helping to increase plant growth [10]. Use of biofertilizer produced from the biodegradation of mackerel wastewater and including a mixture of microbes (mainly Bacillus species) has been verified to be feasible in lab-scale hydroponic cultures of red bean and barley [2]. In the present study, the feasibility of the use of BFW as biofertilizer was examined in field experiments. We conclude that fishmeal wastewater is a good resource to produce biofertilizer and its biodegradation can turn it into a value-added product.

\subsection{Economic Analysis}

After confirmation of the feasibility of the use of BFW as a biofertilizer, economic analysis was performed to estimate the expected profitability from such practical reuse of raw fishmeal wastewater. Uncertainty always remains in economic analysis of a project in the early stages of development, because the level of process detail does not usually allow for an accurate, complete and reliable calculation of these expenses; nevertheless, it is worthwhile, in order to assess process feasibility and identify bottlenecks [27]. The evaluation of the cost of the biofertilizer production was based on the results from this study, and credits for the treatment of both fishmeal wastewater and cells remaining after biodegradation were also considered. Table 4 shows a summary of the economic evaluation. The fixed capital represents the capital necessary for the installation of process equipment, including all the accessories needed to start and operate biodegradation. The cost of equipment for biodegradation (a $1-\mathrm{m}^{3}$ stainless steel bioreactor with stirrer, heating and cooling systems, sampling and drain ports, and sensors) was evaluated to be US $\$ 38,461.50$. When this cost was multiplied by an annuity factor $(k=0.142)$, the equivalent annual cost became US\$5,461.50. A single biodegradation could be run per week, and, thus, the biodegradation equipment cost was calculated to be US\$105.03 per biodegradation. For the biodegradation, auxiliary equipment is necessary, including pumps, oxygen and steam generators, fishmeal wastewater reservoirs, and packing machinery. This equipment cost was evaluated to be US $\$ 19,230.80$, so the equivalent annual cost became US $\$ 2,730.80$ with $k=0.142$. Accordingly, the auxiliary equipment cost was calculated to be US\$52.52 per biodegradation.

For the biofertilizer production, $110 \mathrm{~g}$ of mixed microbes were first prepared to degrade $600 \mathrm{~L}$ of fishmeal wastewater. To harvest $110 \mathrm{~g}$ of seed culture, eleven strains were individually cultivated on nutrient broth (total $972.4 \mathrm{~g}$ ) in 1-L flasks for 1 d. Eleven 1-L flasks were incubated at the same time, and ten times cultivation (total $110 \mathrm{~L}$ ) was necessary because approximately $1 \mathrm{~g}$ of cells was harvested from each 1-L flask culture. During one-time cell culture and harvest, the total handling time (for medium preparation and autoclaving, cell transfer, incubation, and centrifugation) was approximately $6 \mathrm{~h}$, and electricity was required for the balance, autoclave, clean bench, incubator and centrifuge. Considering all these parameters, the cost required for seed culture preparation was US\$473.76. Once the seed culture was inoculated, however, three biodegradations 
Table 4. Cost Evaluation for a Single Biodegradation of Fishmeal Wastewater to Produce Biofertilizer in a $1 \mathrm{~m}^{3}$ Reactor

\begin{tabular}{|c|c|c|c|}
\hline Category & Parameters & Cost (\$) per unit & Cost $(\$)$ \\
\hline \multirow{2}{*}{$\begin{array}{l}\text { Capital investment } \\
\text { cost }\end{array}$} & Biodegradation equipment & $5,461.5 / y$ & 105.03 \\
\hline & Auxiliary equipment & $2,730.8 / y$ & 52.52 \\
\hline \multirow[t]{25}{*}{ Operating cost } & Seed culture (110 g) & & \\
\hline & Culture chemicals (324.1 g) & $0.15 / g$ & 48.62 \\
\hline & Electricity $(69.4 \mathrm{~h})$ & $0.18 / \mathrm{KWh}$ & 12.5 \\
\hline & Water $(36.7 \mathrm{~L})$ & $0.12 / \mathrm{L}$ & 4.4 \\
\hline & Labor (20 h) & $4.62 / \mathrm{h}$ & 92.4 \\
\hline & Raw fishmeal wastewater (600 L) & & \\
\hline & Preheating (3 h) & $0.18 / \mathrm{KWh}$ & 0.54 \\
\hline & Pumping into reactor $(1 \mathrm{~h})$ & $0.18 / \mathrm{KWh}$ & 0.18 \\
\hline & Labor (5 h) & $4.62 / \mathrm{h}$ & 23.1 \\
\hline & Reactor preparation & & \\
\hline & Washing (50 L) & $0.20 / \mathrm{L}$ & 10 \\
\hline & Sterilization $(0.5 \mathrm{~h})$ & $0.18 / \mathrm{KWh}$ & 0.09 \\
\hline & Labor $(1.5 \mathrm{~h})$ & $4.62 / \mathrm{h}$ & 6.93 \\
\hline & Biodegradation (600-L working volume) & & \\
\hline & Electricity (80 h) & $0.24 / \mathrm{KWh}$ & 19.2 \\
\hline & Chemicals (32 g) & $0.15 / g$ & 4.8 \\
\hline & Water $(60 \mathrm{~L})$ & $0.12 / \mathrm{L}$ & 7.2 \\
\hline & Draining $(1 \mathrm{~h})$ & $0.18 / \mathrm{KWh}$ & 0.18 \\
\hline & Labor (83 h) & $4.62 / \mathrm{h}$ & 383.5 \\
\hline & Final product $(560 \mathrm{~L})$ & & \\
\hline & Injection of preservative ( $1 \%$ lactate) & $2.92 / \mathrm{kg}$ & 16.35 \\
\hline & Bottling and packing & $0.14 / \mathrm{L}$ & 78.4 \\
\hline & Labor (2 h) & $4.62 / \mathrm{h}$ & 9.24 \\
\hline & Maintenance & $819.23 / y$ & 15.75 \\
\hline & Fixed operating & $1,228.85 / y$ & 23.63 \\
\hline \multirow[t]{5}{*}{ Credits } & Product value as biofertilizer & $2.22 / \mathrm{L}$ & $-1,243.2$ \\
\hline & Treatment & & \\
\hline & Wastewater (560 L) & $46.15 / \mathrm{m}^{3}$ & -25.84 \\
\hline & Cells (145 g) & $0.10 / \mathrm{kg}$ & -0.015 \\
\hline & Government subsidy & $7,133.36 / y$ & -137.18 \\
\hline Total & & & 491.68 \\
\hline
\end{tabular}

were possible with repeated batch operation without any significant difference in the quality of the product biofertilizer. In this repeated batch operation, $10 \%(\mathrm{v} / \mathrm{v})$ final culture broth including mixed microbes was used as the inoculum for the next batch biodegradation. Therefore, the harvested volume of the final culture broth including mixed microbes became 540 $\mathrm{L}$ in the first and second batches, and the entire $600 \mathrm{~L}$ was harvested in the third batch, which averaged 560 L. The numerical values recorded in Table 4 represent one-third of those required to produce a seed culture. The average cost required for seed-culture preparation was US\$157.92. Before biodegradation, raw fishmeal wastewater was preheated for $3 \mathrm{~h}$ and then pumped into the reactor, requiring a total of 5-h handling time. Therefore, the cost required for raw material preparation was calculated to be US\$23.82. For the biodegradation, the reactor had to be washed and sterilized in advance, and the total handling time for these steps was approximately $1.5 \mathrm{~h}$. The cost required for reactor preparation was calculated to be
US\$17.02.

When seed culture, raw fishmeal wastewater and the reactor were completely prepared, biodegradation started. In the biodegradation, the dominant energy-consuming operation for 80 $\mathrm{h}$ was stirring, and heating/cooling for maintenance of the reactor temperature was next. It was assumed that the operation (including supervision) of the entire biodegradation required a team of two full-time workers in shifts. The total amount of chemicals (antifoaming agent for foam clearance and $\mathrm{NaOH}$ for contamination prevention) used in a single biodegradation was approximately $32 \mathrm{~g}$, and 60-L sterile tap water (approximately $10 \%$ of the total volume) was replenished for deficit water. The handling time for biodegradation (including inoculation, draining the final culture broth, and arrangement) was approximately $83 \mathrm{~h}$. Considering these parameters, the operating cost required per biodegradation was calculated to be US\$414.88.

After harvest of the final culture broth including mixed microbes, processing work is required, which includes injection 
of preservative ( $1 \%$ lactate) into the biofertilizer to maintain its quality during the circulation period [22], bottling and packing. The total handling time for this job was approximately $2 \mathrm{~h}$. The cost of this processing was calculated to be US\$103.99. In the evaluation of operating cost, maintenance costs and fixed operating costs cannot be disregarded. The fixed operating costs include depreciation, taxes, insurance, and so on. Those costs were calculated as 10 and $15 \%$ of the annual capital investment cost, respectively [27]. Thus, the annual maintenance cost and fixed operating cost were calculated to be $\$ 819.23$ and US\$1,228.85, equivalent to US\$15.75 and US\$23.63 per single biodegradation. Based on the calculations, the total manufacturing cost of 560-L biofertilizer per single batch operation was estimated to be US $\$ 914.56$, which corresponds to US $\$ 47,557.12$ per year. At $1 \mathrm{~m}^{3}$-scale production, the greatest cost contribution came from labor (US\$515.17), which accounted for $56.3 \%$ of the total cost, and next was equipment (17.2\%). Utility costs were not influential, although the impact of the individual cost varies greatly with scale [27].

The development of biofertilizer from raw fishmeal wastewater brings some economic benefits, and these were considered as credits in the economic evaluation. Firstly, the final culture broth including mixed microbes $(560 \mathrm{~L})$ is a valuable product as a biofertilizer. Based on the lowest price of liquid amino acid fertilizer on the market (US\$2.22/L), the product is worth US $\$ 1,243.20$. Secondly, the complete reuse of both raw fishmeal wastewater and the remaining cells (as a byproduct) saves on non-negligible waste disposal costs [42]. Currently, the disposal costs for domestic wastewater and solid waste are approximately US $\$ 46.15$ per $\mathrm{m}^{3}$ and US\$0.10 per $\mathrm{kg}$, respectively. This cost is increasing because ocean dumping has been prohibited and other treatment methods, such as landfill and incineration, have strict limitations. Based on the current treatment cost, the credit was evaluated to be US\$25.86 per biodegradation, summed from the reuse of wastewater (US\$25.84 for $560 \mathrm{~L}$ ) and cells (US\$0.02 for $145 \mathrm{~g}$ ). Thirdly, complete reuse of wastewater or solid waste earns a credit (subsidy) from the government. This credit usually corresponds to $15 \%$ of total working expenses in Korea, depending on the scale of equipment, operation and treatment volume [43]. This government policy arose from awareness of the environmental impact of organic wastes. Accordingly, the government encourages recycling of fish-processing waste materials, with enforcement of related regulations, to address such environmental impacts. The government subsidy was evaluated to be US $\$ 137.18$ per single biodegradation, and thus the total financial gain from the complete reuse of the fishmeal wastewater was US $\$ 1,406.24$ per biodegradation. As a result, the expected profitability from practical reuse of raw fishmeal wastewater was estimated to be US\$491.68 per biodegradation, which corresponds to US\$25,567.36 per year. This indicates that the production of liquid biofertilizer from raw fishmeal wastewater can make some profit. However, it is not particularly economically attractive, because this project is in the early stages of development.

In this evaluation, the price of biofertilizer was based on the lowest price of the currently selling organic fertilizers. Since the biofertilizer contains various bioactive compounds and some probiotic bacteria, this profit is expected to increase when the superiority of the biofertilizer becomes known to consumers. Furthermore, larger-scale production would be expected to generate more profit, since larger installations have advantages resulting from economies of scale [44]. This economic analysis result is regarded not only as a useful decision-making tool, but also as a guideline for more detailed assessments.

\section{Conclusions}

Nowadays, complete reuse of fishery waste and wastewater is positively encouraged because the amount of such available waste is gradually increasing with enforcement of environmental regulations. Therefore, biodegradation using specific microbes has been strongly recommended to reuse this waste. On the bases of field experiments and economic analysis at a $1-\mathrm{m}^{3}$ biodegradation scale, the reuse of fishmeal waster as biofertilizer was found to be feasible and potentially profitable. In this study, feasibility of complete reuse of biodegraded fishmeal wastewater as biofertilizer was first reported, and more profit would be expected from larger-scale biodegradation. This effort, following government policy, could establish the basis for the development of resources from marine waste with the creation of added value.

\section{Acknowledgments}

This work was supported by a research grant from Pukyong National University (year 2016). We also express our appreciation to Dongchang Inc. (Busan, Korea) for their assistance in producing the biofertilizer used in this research.

\section{References}

1. Sheriff SA, Balasubramanian S, Baranitharan R, Ponmurugan P. Synthesis and in vitro antioxidant functions of protein hydrolysate from backbones of Rastrelliger kanagurta by proteolytic enzymes. Saudi J. Biol. Sci. 2014;21:19-26.

2. Jung HY, Kim JK. Eco-friendly zero-waste management of mackerel wastewater and enhancement of its reutilization value. Int. Biodeter. Biodegr. 2016;111:1-13.

3. Figueroa JG, Jung HY, Jeong GT, Kim JK. The high reutilization value potential of high-salinity anchovy fishmeal wastewater through microbial degradation. World J. Microbiol. Biotechnol. 2015;31:1575-1586.

4. Yadav A, Gang VK. Recycling of organic wastes by employing Eisenia fetida. Bioresour. Technol. 2011;102:2874-2880.

5. Gunes A, Turan M, Gulluce M, Sahin F. Nutritional content analysis of plant growth-promoting rhizobacteria species. Eur. J. Soil Biol. 2014;60:88-97.

6. Maeda H, Dudareva N. The shikimate pathway and aromatic amino acid biosynthesis in plants. Annu. Rev. Plant Biol. 2012;63:73-105. 
7. Miret JA, Munne-Bosch S. Plant amino acid-derived vitamins: Biosynthesis and function. Amino Acids 2014;46:809-824.

8. Carbonell GR, de Imperial $\mathrm{M}$, Torrijos $\mathrm{M}$, Delgado $\mathrm{M}$, Rodriguez JA. Effects of municipal solid waste compost and mineral fertilizer amendments on soil properties and heavy metals distribution in maize plants (Zea mays L.). Chemosphere 2011;85:1614-1623.

9. Wu SC, Cha ZG, Cheung KC, Wong MH. Effects of biofertilizer containing $\mathrm{N}$-fixer, $\mathrm{P}$ and $\mathrm{K}$ solubilizers and AM fungi on maize growth: A greenhouse trial. Geoderma 2005;125: 155-166.

10. Mohammadi K, Sohrabi Y. Bacterial biofertilizers for sustainable crop production: A review. ARPN J. Agri. Biol. Sci. 2012;7:307-316.

11. Khan N, Mishra A, Chauhan PS, Nautiyal CS. Induction of Paenibacillus lentimorbus biofilm by sodium alginate and $\mathrm{CaCl}_{2}$ alleviates drought stress in chickpea. Ann. App. Biol. 2011;159:372-386.

12. Nautiyal CS, Srivastava S, Chauhan PS, Seem K, Mishra A, Sopory SK. Plant growth-promoting bacteria Bacillus amyloliquefaciens NBRISN13 modulates gene expression profile of leaf and rhizosphere community in rice during salt stress. Plant Physiol. Biochem. 2013;66:1-9.

13. Siddikee MA, Glick BR, Chauhan PS, Yima WJ, Sa T. Enhancement of growth and salt tolerance of red pepper seedlings (Capsicum annuum L.) by regulating stress ethylene synthesis with halotolerant bacteria containing 1-aminocyclopropane-1-carboxylic acid deaminase activity. Plant Physiol. Biochem. 2013;49:427-434.

14. Mandic-Mulec I, Prosser JI. Diversity of endospore-forming bacteria in soil: Characterization and driving mechanisms. In: Loganand NA, de Vos P, eds. Endospore-forming soil bacteria. London: Springer; 2011. p. 31-59.

15. Calvo P, Watts DB, Ames RN, Kloepper JW, Torbert HA. Microbial-based inoculants impact nitrous oxide emissions from an incubated soil medium containing urea fertilizers. J. Environ. Qual. 2012;42:704-712.

16. Chaabouni I, Guesmi A, Cherif A. Secondary metabolites of Bacillus: Potentials in biotechnology. In: Sansinenea E, ed. Bacillus thuringiensis biotechnology. Dordrecht: Springer; 2012. p. 347-366.

17. Dao VT, Kim JK. Scaled-up bioconversion of fish waste to liquid fertilizer using a $5 \mathrm{~L}$ ribbon-type reactor. J. Environ. Manage. 2011;92:2441-2446.

18. Gwon BK, Kim JK. Feasibility study on production of liquid fertilizer in a $1 \mathrm{~m}^{3}$ reactor using fishmeal wastewater for commercialization. Environ. Eng. Res. 2012;17:3-8.

19. Mathews JA. Green growth strategies: Korean initiatives. Futures 2012;44:761-769.

20. Meyer-Aurich A, Griffin TW, Herbst R, Giebel A, Muhammmad N. Spatial econometric analysis of a field-scale site-specific nitrogen fertilizer experiment on wheat (Triticumaestuvum L.) yield and quality. Comput. Electron. Agr. 2010;74:73-79.

21. Kim JK, Kim JB, Cho KS, Hong YK. Isolation and identification of microorganisms and their aerobic biodegradation of fish-meal wastewater for liquid-fertilization. Int. Biodeter.
Biodegr. 2007;59:156-165.

22. Kim JK, Dao VT, Kong IS, Lee HH. Identification and characterization of microorganisms from earthworm viscera for the conversion of fish wastes into liquid fertilizer. Bioresour. Technol. 2010;101:5131-5136.

23. Neter J, Wasserman W, Kutner MH. Applied linear statistical models. 2nd ed. Homewood: Irwin; 1985.

24. Tufvesson P, Ekmana A, Sardarib RRR, Engdahla K, Tufvesson L. Economic and environmental assessment of propionic acid production by fermentation using different renewable raw materials. Bioresour. Technol. 2013;149:556-564.

25. Sanchez-Segado S, Lozano LJ, de Los Rios AP, HernandezFernandez FJ, Godinez C, Juan D. Process design and economic analysis of a hypothetical bioethanol production plant using carob pod as feedstock. Bioresour. Technol. 2012;104: 324-328.

26. Nielsen J, Villadsen J, Liden G. Bioreaction engineering principles. 2nd ed. New York: Kluwer Academic; 2003.

27. Tufvesson P, Lima-Ramos J, Nordblad M, Woodley JM. Guidelines and cost analysis for catalyst production in biocatalytic processes. Org. Process Res. Dev. 2011;15:266-274

28. Ruiz G, Jeison D, Chamy R. Development of denitrifying and methanogenic activities in USB reactors for the treatment of wastewater: Effect of $\mathrm{COD} / \mathrm{N}$ ratio. Process Biochem. 2006;41:1338-1342.

29. Wang L, Zhang B, Han J, Zheng Y, Li J, Shan A. Optimization of hydrolysis condition of blood meal by Bacillus subtilis with response surface methodology. Int. Biodeter. Biodegr. 2015;104:112-117.

30. Zhang Z, Zhu J, Park KJ. Effects of duration and intensity of aeration on solids decomposition in pig slurry for odor control. Biosyst. Eng. 2004;89:445-456.

31. Nges IA, Mbatia B, Bjornsson L. Improved utilization of fish waste by anaerobic digestion following omega-3 fatty acids extraction. J. Environ. Manage. 2012;110:159-165.

32. Lian S. Combined use of chemical and organic fertilizer. Technical Bulletin No. 11: Malaysia and Food and Fertilizer Technology Centre, University Pertanian, Taiwan; 1994.

33. Arvanitoyannis IS, Kassaveti A. Fish industry waste: Treatments, environmental impacts, current and potential uses. Int. J. Food Sci. Technol. 2008;43:726-745.

34. Reeve JR, Smith JL, Carpenter-Boggs LC, Reganold JP. Soil-based cycling and differential uptake of amino acids by three species of strawberry (Fragaria spp.) plants. Soil Biol. Biochem. 2008;40:2547-2552.

35. Amir R, Hacham Y, Galili G. Cystathionine $\gamma$-synthase and threonine synthase operate in concert to regulate carbon flow towards methionine in plants. Trends Plant Sci. 2002;7: 153-156.

36. Babu AG, Kim JD, Oh BT. Enhancement of heavy metal phytoremediation by Alnus firma with endophytic Bacillus thuringiensis GDB-1. J. Hazard. Mater. 2013;250/251:477-483.

37. Tsouvaltzis P, Koukounaras A, Siomos AS. Application of amino acids improves lettuce crop uniformity and inhibits nitrate accumulation induced by the supplemental inorganic nitrogen fertilization. Int. J. Agr. Biol. 2014;16:951-955.

38. Peng Z, Huang J, Yu J, Li W, Yang L, Lin Z. Effect of foliar 
application of amino acid on the quality and enzyme activity of flowering Chinese cabbage (Brassica parachinensis Bailey). Hu'nan Agr. Sci. Technol. Nesl. 2011;12:50-53.

39. El-Nahhal Y, Tubail K, Safi M, Safi J. Effect of treated waste water irrigation on plant growth and soil properties in Gaza Strip, Palestine. Am. J. Plant Sci. 2013;4:1736-1743.

40. Galieni A, Stagnari F, Speca S, Pisante M. Leaf traits as indicators of limiting growing conditions for lettuce (Lactuca sativa). Ann. Appl. Biol. 2016;169:342-356.

41. Masters GM, Ela WP. Introduction to environmental engineering and science. 3rd ed. New Jersey: Pearson Prentice Hall;
2008.

42. Heinzle E, Biwer AP, Cooney CL. Development of sustainable bioprocesses: Modeling and assessment. New York: Wiley; 2006.

43. Lee JS, Cho JH, Kim DY, Hwang JH. Strategies for eco-friendly utilization and industrialization of fishery by-products. Busan: Korea Maritime Institute; 2013.

44. Amigun B, von Blottnitz H. Investigation of scale economics for African biogas installations. Energ. Convers. Manage. 2007;48:3090-3094. 